\title{
PSYCHE.
}

\section{LIFE HISTORY OF CLISIOCAMPA PLUVIALIS DYAR.}

BY HARRISON G. DYAR, A. M., NEW YORK.

C. Pluvialis Dyar.

I 883 - Stretch, Papilio, iii, 20 (as larva no. I).

I893 - Dyar, Can. entom., xxv, 42 .

I have been enabled to complete the life history of this species through the kindness of Prof. O. B. Johnson of Seattle, and Prof. C. V. Piper of Pullman, Washington.

Both of these gentlemen have sent me eggs and examples of the moth.

C. pluvialis occurs throughout the Pacific Northwest where it represents fragilis. I have found the nests at Victoria, B. C. on Vancouver Island, at Tacoma and Seattle in Washington, and Portland, Oregon. It is recorded from Astoria, Oregon by Mr. R. H. Stretch, and sent me by $\mathrm{Mr}$. Piper from Pullman, Washington.

The fully marked larvae look strikingly different from fragilis, yet the two are exactly alike in pattern, and whereas in pluvialis the orange marks are greatly developed and the blue reduced, in fragilis the orange is reduced almost to obliteration and the blue greatly extended. Mr. Stretch has noted a considerable range of varia- tion in the Astoria larvae. He says that they varied by the expansion or contraction of the dorsal orange markings, and in the latter case the blue became strikingly visible. This is a greater range of variation than $I$ have happened to observe in any one locality, but the specimens sent me by Mr. Piper have the orange considerabiy reduced.

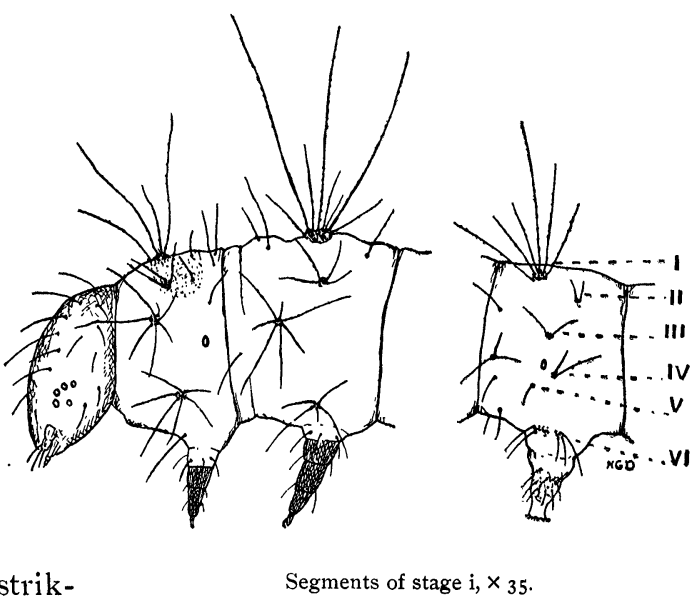

I suspect that as we go East the orange marks will tend to be supplanted by the blue, and this species will grade into fragilis. However, I have yet to see larvae which are not definitely one or the other, and the moths seem not to pass into each other, though the Idaho region is still to be explored. 
Eggs. The eggs are as usual in the genus. The ring-like masses are large, quite prom. inent and well covered with the usual frothy varnish. They appear to be deposited around the smaller twigs.

First stage. Entirely black with long pale hairs, finely barbed. Under a half inch objective small luteous subdorsal patches appear on the posterior margin of each segment, except at the extremities. Head black, not shining, width $0.4 \mathrm{~mm}$. As the stage advances, the subdorsal patches become more distinct, especially on joints 5-10. They are triangular in shape, the base directed posteriorly. Subventral region pale. The arrangement of the warts is shown in the accompanying figure* magnified thirty-five diameters.

Second stage. Head dull black, width about $0.6 \mathrm{~mm}$. Body black, the subdorsal orange patches as before or larger, but not extending cephalad of the large black wart $i$. Orange lateral and substigmatal lines now appear and slight traces of a subventral line, but all obscure and obsolete at both extremities. The subdorsal patches vary in width and may even reach the lateral line. Hairs faintly reddish, a little paler subventrally. Wart iv and the secondary one before the spiracle conspicuous; secondary hairs also present, but small.

Third stage. Head round, black, not shining; width 1.0-1.3 mm. Body black, marked as before, but the orange marks are greatly extended, the subdorsal patches reach the front part of the segment, or are divided into two by wart $i$; lateral lines broadened and diffused, so that most of the side is covered by orange mottlings. A series of narrow,

* In Journal N. Y. ent. soc. iii, 23, I described the setae in stage $\mathrm{i}$ of the genus Clisiocampa, using my notes on fragilis. $\mathrm{My}$ description is quite erroneous, as the figure shows, as my magnification was insufficient at that time. My description should be replaced by the figure. It will be noted that the arrangement beautifully corroborates the points which I was trying to establish. The series of hairs along the anterior edge of the abdominal segments are secondary, and the primitive first stage is wanting. elliptical, segmentary, dorsal, blue patches. Hair reddish.

Fourth stage. Head round, black, hairy! width $\mathrm{r} .6-\mathrm{r} .8 \mathrm{~mm}$. The dorsal blue spots form a broken line, on each side of which are the two orange spots on each segment, the posterior one large and irregularly triangular. A diffuse and mottled pale orange lateral line and many irregular orange mottlings, laterally and subventrally. The subdorsal blue dots now appear, but small, two on each segment situated above the lateral line.

Fifth stage. As in the next stage. Width of head $2.2-2.6 \mathrm{~mm}$.

Sixth stage. Width of head $3.2 \mathrm{~mm}$. I have already described this stage. (Can. ent $x x v, 42$.) It will be noticed that the evolution of the markings of $C$. pluvialis is very direct. The original pattern is outlined when the larva hatches and is merely increased and supplemented by the small blue marks as development proceeds. This is to be contrasted with the evolution of fragilis (Psyche vii, 189). C. fragilis starts with the same pattern as pluvialis, but in the third stage the course of development is abruptly changed, the orange is reduced and the supplementary blue marks afterward predominate. C. pluvialis seems to be the most generalized of our Clisiocampa larvae in respect to its markings.

Cocoon and pupa as usual in the genus. The pupa is cylindrical, the thorax and cases small, the abdomen large centrally, the last segment pointed, but blunt and without cremaster. Color black, hardly shining, covered sparsely with reddish pile except on the cases.

Food plants. Alder (Alnus), apple and Crataegus and also cherry, currant, bramble and rose, according to Stretch.

The nests are not large, but compact. One measured was $130 \mathrm{~mm}$. long and $90 \mathrm{~mm}$. broad at the top. 

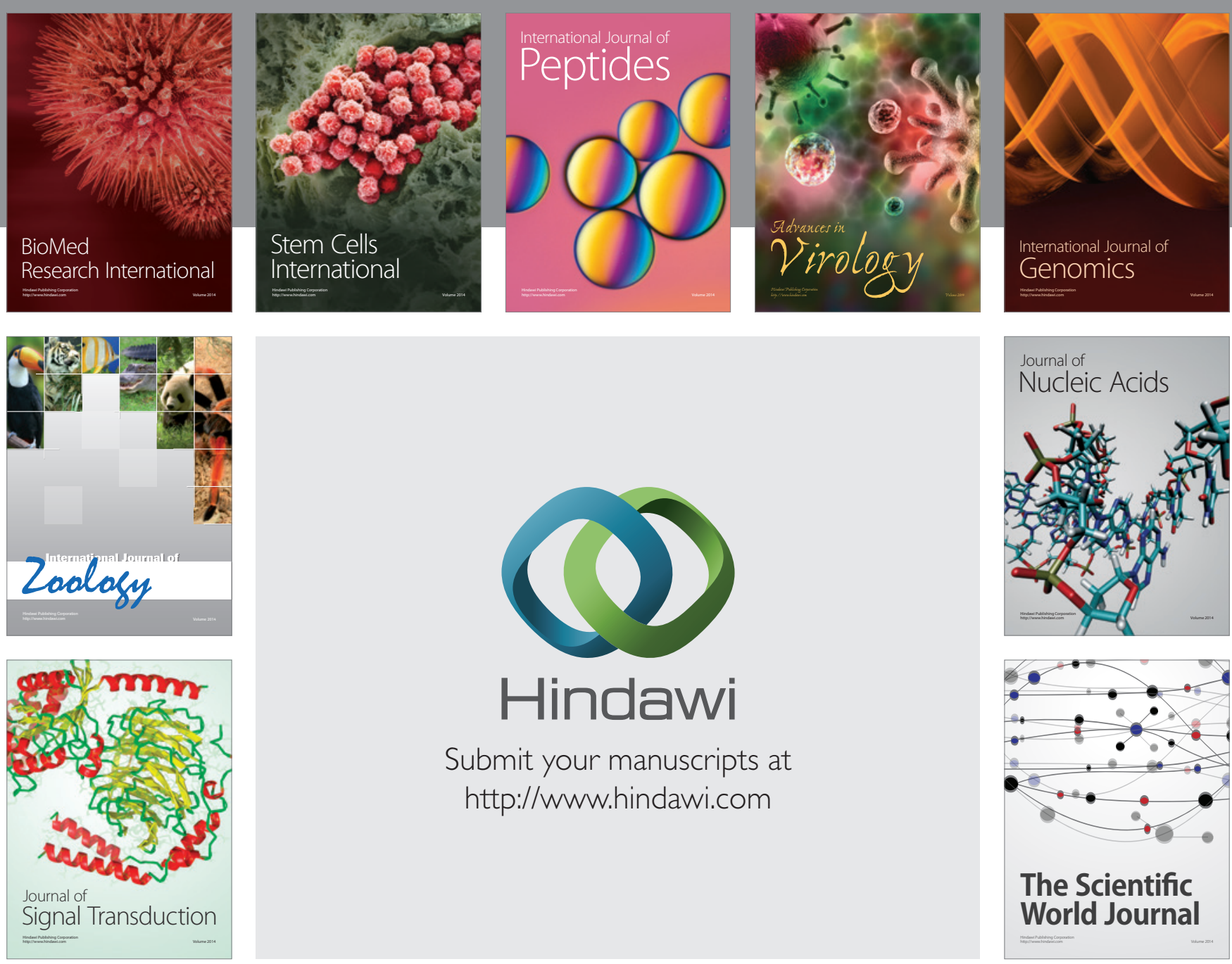

Submit your manuscripts at

http://www.hindawi.com
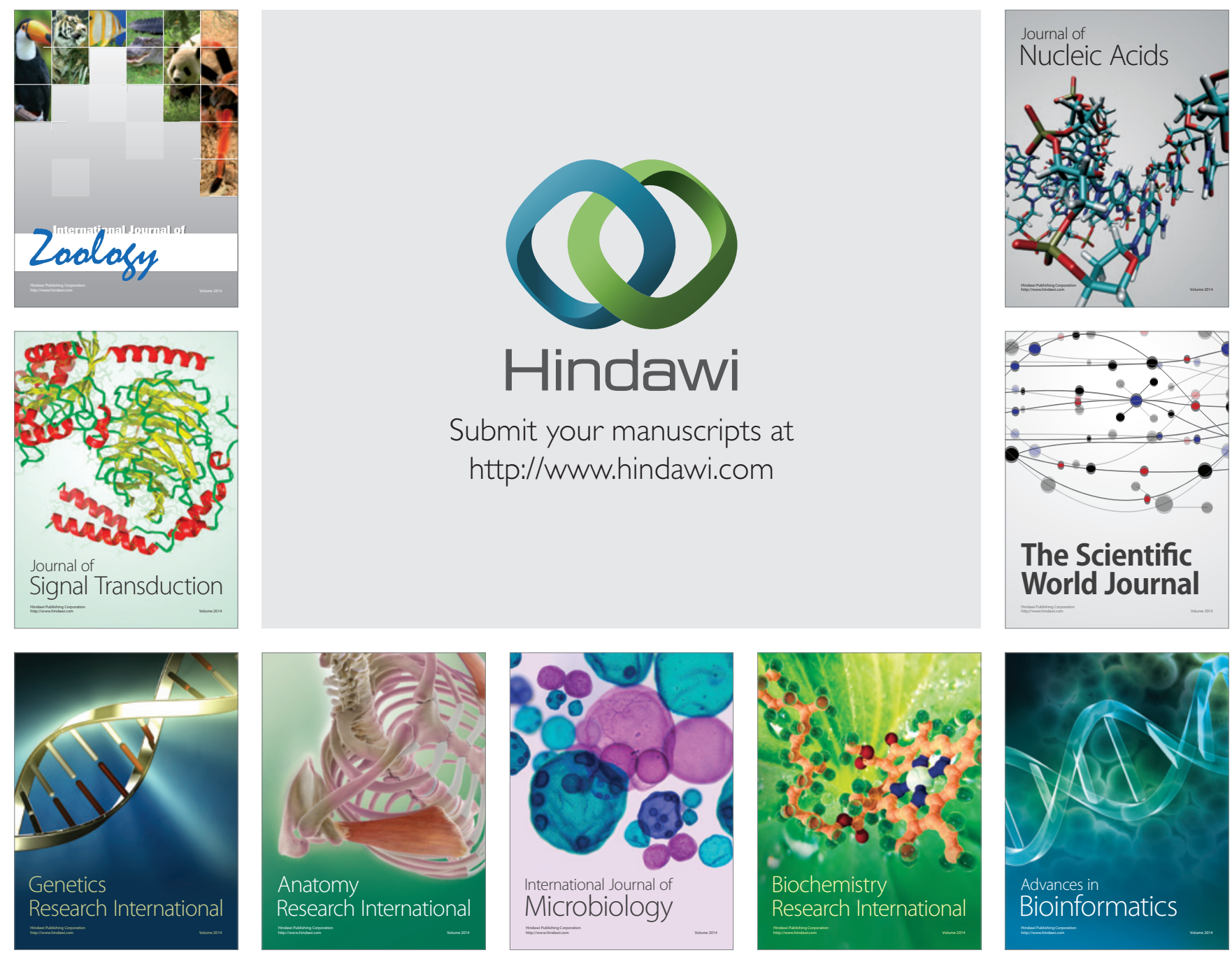

The Scientific World Journal
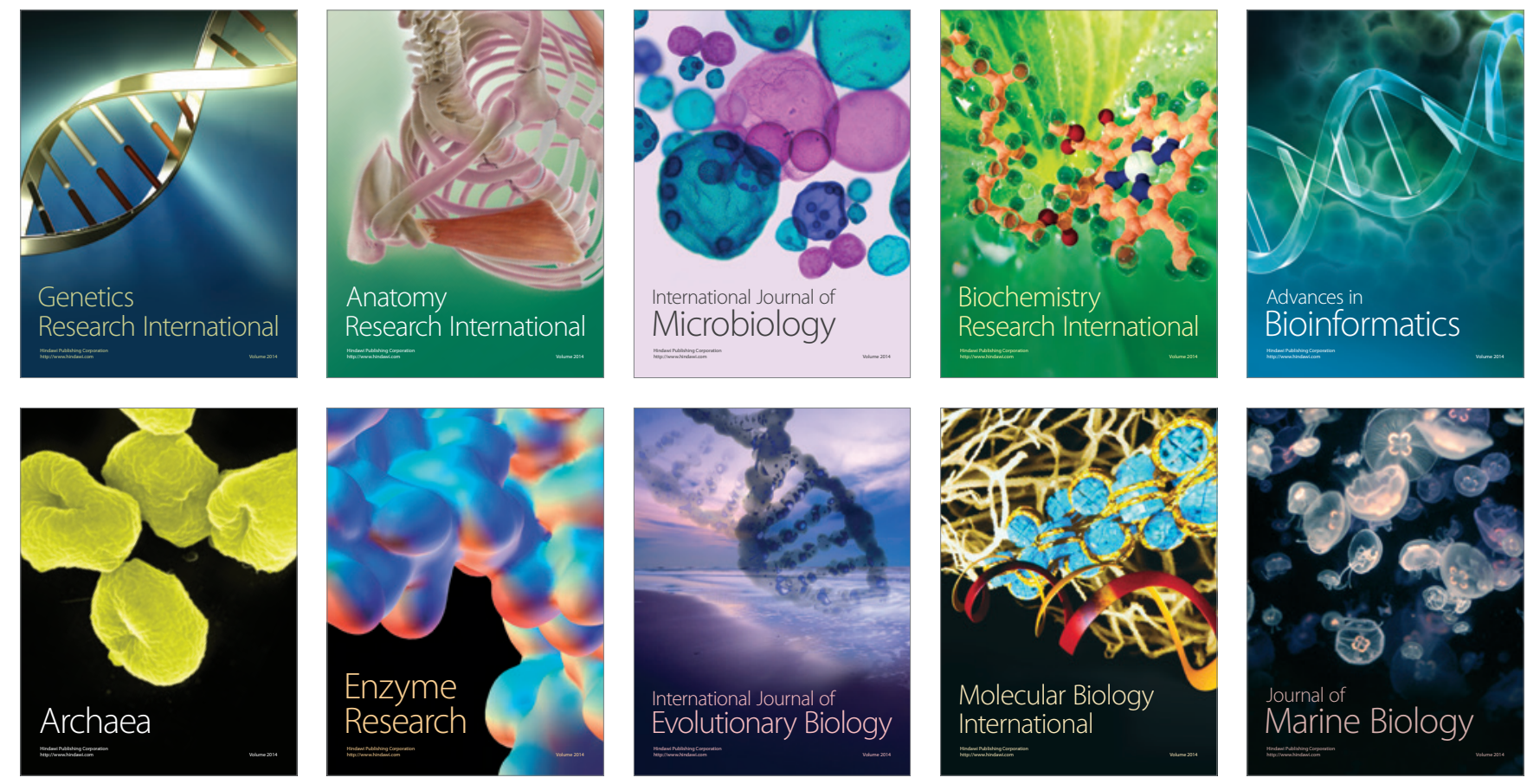